\title{
Postoperative outcome of body core temperature rhythm and sleep-wake cycle in third ventricle craniopharyngiomas
}

\author{
*Matteo Zoli, MD,' Luisa Sambati, MD, PhD, 2,3 Laura Milanese, MD, ${ }^{1}$ Matteo Foschi, MD, ${ }^{2,3}$ \\ Marco Faustini-Fustini, MD, ${ }^{1}$ Gianluca Marucci, MD, PhD, ${ }^{4}$ Dario de Biase, $\mathrm{PhD},{ }^{5}$ \\ Giovanni Tallini, MD, ${ }^{6}$ Annagrazia Cecere, MSc, ${ }^{3}$ Francesco Mignani, MSc, ${ }^{3}$ Carmelo Sturiale, MD, ${ }^{1}$ \\ Giorgio Frank, MD, ${ }^{1}$ Ernesto Pasquini, MD, ${ }^{7}$ Pietro Cortelli, MD, PhD, ${ }^{2,3}$ Diego Mazzatenta, MD, ${ }^{1}$ and \\ Federica Provini, MD, PhD ${ }^{2,3}$
}

\begin{abstract}
${ }^{1}$ Center of Surgery for Pituitary Tumors and Endoscopic Skull Base Surgery, Department of Neurosurgery, IRCCS Istituto delle Scienze Neurologiche; '2Department of Biomedical and Neuromotor Sciences, University of Bologna; ${ }^{3}$ RCCS Institute of Neurological Sciences of Bologna, Bellaria Hospital; ${ }^{4}$ Anatomic Pathology, Bellaria Hospital, University of Bologna; ${ }^{5}$ Department of Pharmacology and Biotechnology, University of Bologna; ${ }^{6}$ Department of Medicine, Anatomic Pathology-Molecular Diagnostic Unit, Azienda Sanitaria Locale of Bologna, University of Bologna School of Medicine; and ${ }^{7}$ Ear, Nose and Throat Department, Bellaria Hospital, Bologna, Italy
\end{abstract}

OBJECTIVE One of the more serious risks in the treatment of third ventricle craniopharyngiomas is represented by hypothalamic damage. Recently, many papers have reported the expansion of the indications for the endoscopic endonasal approach (EEA) to be used for these tumors as well. The aim of this study was to assess the outcome of sleep-wake cycle and body core temperature (BCT), both depending on hypothalamic control, in patients affected by craniopharyngiomas involving the third ventricle that were surgically treated via an EEA.

METHODS All consecutive adult patients with craniopharyngiomas that were treated at one center via an EEA between 2014 and 2016 were prospectively included. Each patient underwent neuroradiological, endocrinological, and ophthalmological evaluation; 24-hour monitoring of the BCT rhythm; and the sleep-wake cycle before surgery and at follow-up of at least 6 months.

RESULTS Ten patients were included in the study (male/female ratio 4:6, mean age 48.6 years, SD 15.9 years). Grosstotal resection was achieved in 8 cases. Preoperative BCT rhythm was pathological in 6 patients. After surgery, these disturbances resolved in 2 cases, improved in another 3, and remained the same in 1 patient; also, 1 case of de novo onset was observed. Before surgery the sleep-wake cycle was pathological in 8 cases, and it was restored in 4 patients at follow-up. After surgery the number of patients reporting diurnal naps increased from 7 to 9 .

CONCLUSIONS The outcome of the sleep-wake cycle and BCT analyzed after EEA in this study is promising. Despite the short duration of the authors' experience, they consider these results encouraging; additional series are needed to confirm the preliminary findings.

https://thejns.org/doi/abs/10.3171/2016.9.FOCUS16317

KEY WORDS craniopharyngioma; hypothalamus; endoscopic endonasal approach; sleep-wake cycle; body core temperature rhythm; body mass index

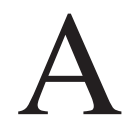
MONG the different challenges that craniopharyngiomas can present for the specialists involved in their treatment, such as neurosurgeons, neuroendocrinologists, neurologists, ENT surgeons, neuroradiologists, and neuropathologists, the risk of hypothalamic damage is one of the more demanding and the one with the

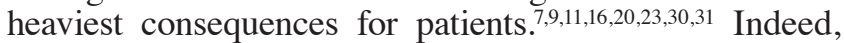
damage to the hypothalamic function can be disastrous for the patient, possibly causing autonomic disorders such as circadian rhythm deregulation, cognitive disorders such

ABBREVIATIONS BCT = body core temperature; $\mathrm{BMI}=$ body mass index; $\mathrm{DI}$ = diabetes insipidus; EEA = endoscopic endonasal approach; $\mathrm{GTR}$ = gross-total resection; MESOR = Midline Estimating Statistic of Rhythm; PTR = partial tumor resection.

SUBMITTED August 1, 2016. ACCEPTED September 13, 2016.

INCLUDE WHEN CITING DOI: 10.3171/2016.9.FOCUS16317.

* Drs. Zoli and Sambati contributed equally to this work. 
as memory dysfunction and behavioral modifications, relevant weight alterations, and anterior and/or posterior pituitary insufficiencies. ${ }^{7,9,11,16,20,23,30,31}$ Recently, many papers have reported the adoption of the endoscopic endonasal approach (EEA) for suprasellar craniopharyngiomas involving the third ventricle. ${ }^{2-4,8,21}$ These authors have demonstrated in large series the feasibility and safety of this approach for such baffling tumors. ${ }^{2-4,8,21}$ However, few data about the outcome of the functions involving the hypothalamus after surgery are available, and in particular data regarding the body core temperature (BCT) rhythm and sleep-wake cycle., ${ }^{1,5,6,9,11,15,22,28}$

The aim of this study was to investigate the outcome of the BCT rhythm and sleep-wake cycle dysfunctions in patients with craniopharyngiomas involving the third ventricle undergoing operation via an EEA.

\section{Methods}

Data on all adult patients undergoing endoscopic endonasal surgery at our Center of Surgery for Pituitary Tumors and Endoscopic Skull Base Surgery at the Institute of Neurological Sciences of Bologna, Italy, for tumors involving the third ventricle were prospectively collected over a 2-year period, from 2014 to 2016. Approval of the study was received from the University of Bologna's ethics committee. All cases were surgically treated by the senior neurosurgeon (D.M.) and senior ENT surgeon (E.P.). Inclusion criteria consisted of 1) neuroradiological evidence of hypothalamic involvement by the tumor on MRI studies obtained with gadolinium, and 2) use of the EEA. Exclusion criteria consisted of 1) earlier surgery or radiotherapy, 2) age younger than 18 years, and 3) followup of less than 6 months. Of the 12 cases enrolled in the study, 2 patients were excluded for a histological diagnosis different from the preoperatively suspected craniopharyngioma. Each patient underwent a clinical interview with particular attention to the sleep-wake cycle and body temperature disturbances.

At preoperative MRI, tumors were classified depending on their location as either infundibulo-tuberal (or not strictly intraventricular) or purely endoventricular. ${ }^{25-27,29}$ According to Pascual et al., the first group includes those tumors arising from the pituitary stalk at its upper part, and thus extending primarily suprasellarly and involving the third ventricle floor during their growth, and the second group includes completely intraventricular lesions. ${ }^{25-27,29}$ The involvement of hypothalamus was divided into anterior and/or posterior considering the extension of the tumor in relation to the mammillary bodies. ${ }^{24}$ Followup MRI studies were obtained 3 months after surgery to assess the degree of tumor removal and after 12 months to detect any recurrences.

For histological evaluation tissue was fixed in $10 \%$ buffered formalin, embedded in paraffin, and routinely stained for $\mathrm{H} \& \mathrm{E}$. In all enrolled cases, availability of paraffinembedded material for molecular characterization was required. The DNA was extracted from 5 formalin-fixed paraffin-embedded $10-\mu \mathrm{m}$-thick sections scraped under microscope guidance.

Before beginning the molecular analysis, in all the cas- es, 2 pathologists (G.M. and G.T.) performed an accurate estimation of the proportion of lesional cells/total number of cells (i.e., lesional cell enrichment) in the dissected area. Approximately 10 ng of DNA was used for each amplification reaction according to a previously described protocol, and with primers specific for $B R A F$ exon 15 and for CTNNB1 exon $3 .{ }^{17,18}$ Only nucleotide variations observed in both strands, with at least $1 \%$ of allele-read frequency at the position, were considered mutations.

Endocrinological evaluation consisted of baseline tests-serum prolactin, cortisol, TSH (thyroid-stimulating hormone), ACTH (adrenocorticotropic hormone), free $\mathrm{T}_{4}$ (thyroxine), GH (growth hormone), LH (luteinizing hormone), FSH (follicle-stimulating hormone), and total testosterone in men and estradiol in women-together with investigation for the possible occurrence of diabetes insipidus (DI)-24-hour urine volume; serum and urine osmolality; urine sodium; serum sodium, chlorine, and potassium; and clinical evaluation of dehydration, extracellular volume status, and sense of thirst. Urine samples collected continuously over a 24-hour period in the first days after surgery were also analyzed for measurement of urinary catecholamine metabolites. These tests were repeated at 1 and 3 months after surgery. Preoperative ophthalmological evaluation consisted of acuity and visual field measurement, repeated at 3 and 6-12 months after surgery.

The BCT was evaluated by continuously monitoring rectal temperature every 2 minutes for 24 hours using a Mini-logger portable device..$^{19}$ With this procedure, it is possible to determine whether there is a rhythm within a 24-hour period $(p<0.05)$ and to evaluate the following parameters with their $95 \%$ confidence limits: 1) Midline Estimating Statistic of Rhythm (MESOR): rhythm adjusted to the 24-hour average; 2) amplitude: the difference between the maximum value measured at the acrophase and the MESOR in the cosine curve; and 3) acrophase: lag between reference time (24:00) and time of highest value of the cosine function used to approximate the rhythm. The BCT was defined as pathological if one of the 3 parameters (MESOR, amplitude, or acrophase) was clearly impaired with respect to control values obtained in our laboratory in 10 age-matched controls (mean age \pm SD: $32.4 \pm 8.5$ years).

All patients underwent a 24-hour sleep-wake cycle recording to obtain an objective quantification of the sleep and wake durations and distributions throughout the 24 hours. This recording included electroencephalogram (C3-A2, O2-A1, Cz-A1), right and left electrooculogram, electrocardiogram, and electromyogram of the mylohyoideus and the left and right tibialis muscles. Sleep stages were scored for 30-second epochs according to the American Academy of Sleep Medicine criteria. ${ }^{13}$ Sleep efficiency (the ratio between the total sleep time and the total sleep period) was calculated and defined as pathological if it was $<85 \%$. The number and duration of diurnal naps were also calculated considering their distribution throughout the daytime period and the phase of sleep onset. The 24-hour BCT and sleep-wake cycle monitoring were performed after a biochemical demonstration of the efficacy of the hormone replacement therapy, to avoid any confounding results due to a partial or complete hypopituitarism. 
All patients underwent neurological examination, including body mass index (BMI) assessment, before surgery and at 3 and 6-12 months postoperatively. Surgical complications have been considered and their sequelae reported in the study. Data have been analyzed using a pure descriptive statistical method.

\section{Surgical Technique}

Our endoscopic endonasal surgical technique for craniopharyngiomas has been described elsewhere. ${ }^{12}$ In brief, the patient is placed in the semisitting position, with the thorax slightly elevated on the operating table. The laryngopharynx is packed with gauze to prevent blood and fluid passage into the upper respiratory tract. Rod lens endoscopes (4 $\mathrm{mm}$ in diameter, $18 \mathrm{~cm}$ in length, with $0^{\circ}$ and $30^{\circ}$ scope; Hopkins II-Karl Storz Endoscopy-America, Inc.) with a high-definition camera were used. The middle turbinate of the narrowest nasal fossa is resected while the contralateral one is laterally displaced. Then a posterior septostomy is performed to work through both nostrils.
When necessary, a unilateral anterior and posterior ethmoidectomy to expose the posterior wall of the sphenoid is followed by a wide anterior sphenoidotomy. Indeed, in selected cases with wide sphenoid pneumatization, the ethmoidectomy can be avoided. Based on intraoperative anatomical landmarks (i.e., optic-carotid recess) the bony floor of the sella is identified and progressively removed with a high-speed diamond drill or a Kerrison rongeur (Fig. 1). Bone removal is extended superiorly to the tuberculum sellae and planum sphenoidalis. The intercavernous sinus is coagulated and then the dura mater is opened superiorly to expose the suprasellar cistern. For the intradural phase of the surgery, we prefer to fix the endoscope with a holder to adopt a "4-hands" technique.

The tumor removal is performed according to the principles of the microsurgical technique. The tumor is initially debulked centrally, then it is dissected from the surrounding arachnoid layer (Fig. 2). This allows preservation of the arachnoid covering the optic nerves and their tiny feeding vessels and the superior hypophyseal artery. The tumor is finally progressively dissected from the hypothal-

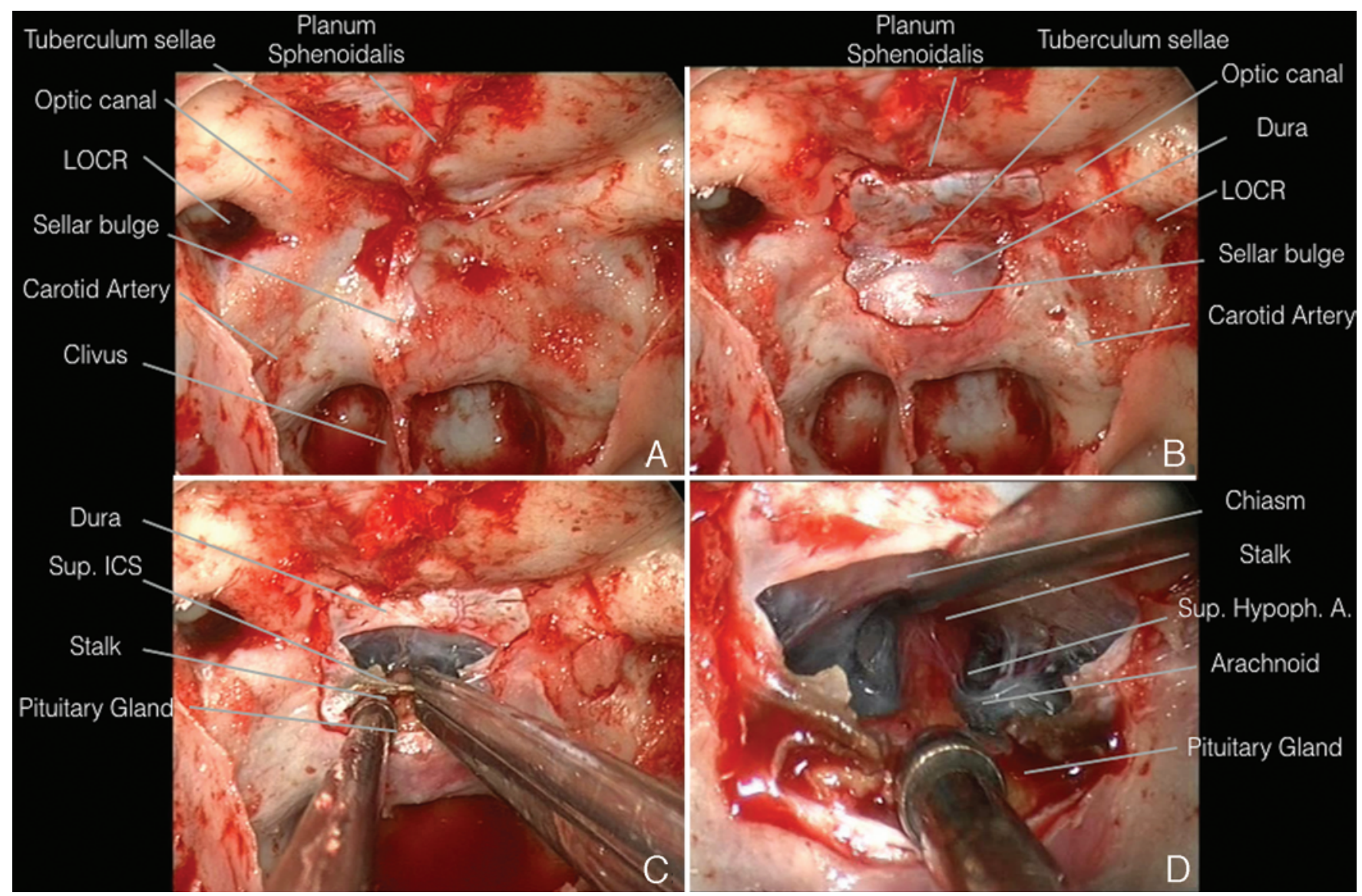

FIG. 1. Intraoperative endoscopic endonasal images obtained using a $0^{\circ}$ scope. The different steps of the extended EEA are illustrated. A: The anatomy of the posterior wall of the sphenoidal sinus can be observed. The main landmarks of this approach are represented by the sellar bulge, the optic canals, and the internal carotid artery protuberances. B: The bone removal is performed from the sellar bulge and it extends superiorly to the tuberculum sellae and laterally up to the medial border of the optic canals. C: After coagulation, the superior intercavernous sinus can be cut. An inverted $\mathrm{H}$-shaped incision is routinely used in our center to open the dura at this level. D: The access provided by the extended EEA is shown. The suprasellar region anatomical structures can be recognized. LOCR = left optic-carotid recess; Sup. Hypoph. A. = superior hypophyseal artery; Sup. ICS = superior intercavernous sinus. 


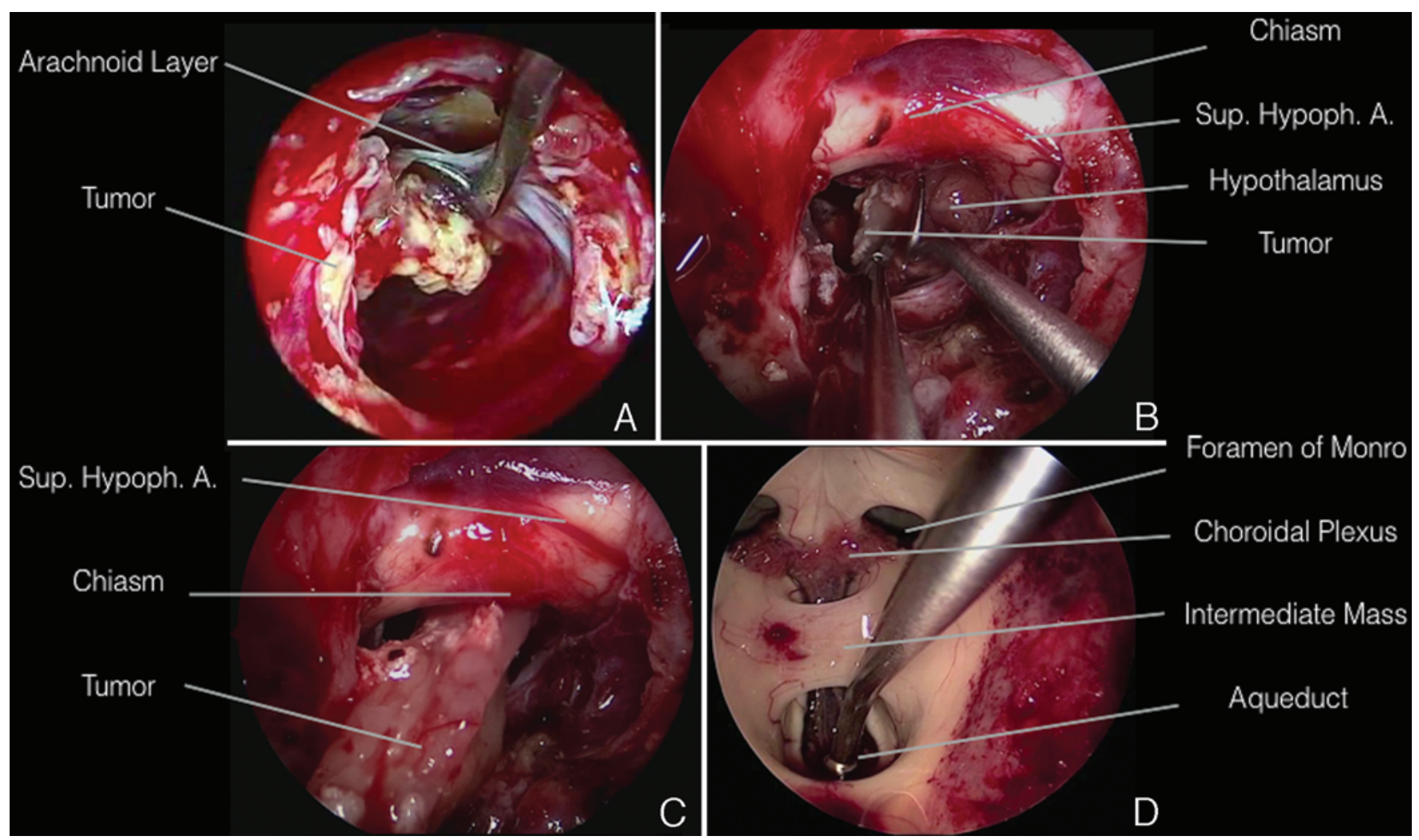

FIG. 2. Intraoperative endoscopic endonasal images obtained using a $0^{\circ}$ scope. The tumor removal phases are illustrated. A: The tumor can be removed, using the arachnoid layer as cleavage plane. This allows us to reduce the risk of damage to the neurovascular structures of the area. B and C: The removal of the tumor from the hypothalamus can be performed with the standard bimanual microsurgical technique. After central debulking, the tumor can be progressively removed, avoiding any traction or direct manipulation of the hypothalamic structures. D: The surgical exploration of the third ventricle during the tumor removal allows us to remove any tumor remnant.

amus, but in case of intrapial infiltration this maneuver is abandoned to avoid permanent neurological sequelae. At the end of the tumor removal an exploration of the surgical cavity is usually performed through angled scopes.

A watertight dural repair is performed with the freeflap multilayer technique, using fascia lata and mucoperi- osteum, or with a nasoseptal flap (Fig. 3). A single 8-cm Merocel pack is inserted in each nostril (Merocel Corp.).

\section{Results}

Ten patients were included in the study; 6 were women

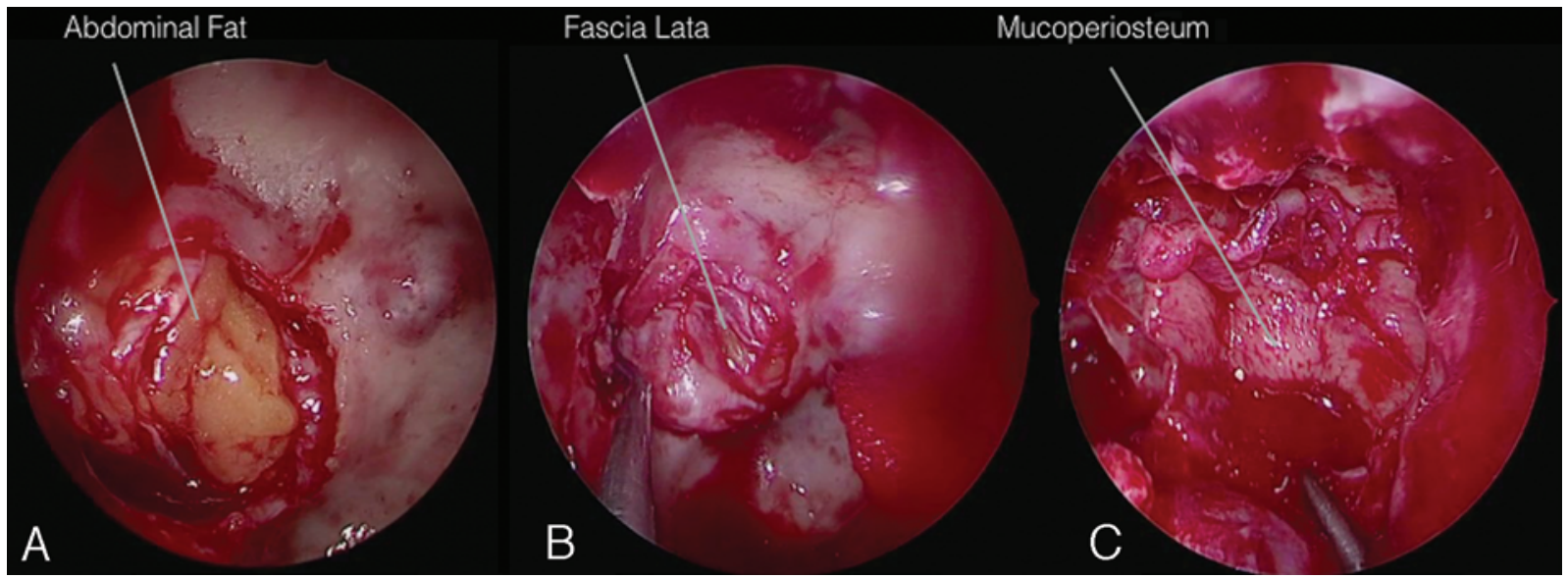

FIG. 3. Intraoperative endoscopic endonasal images obtained using a $0^{\circ}$ scope. Dural repair. A: We prefer a multilayer dural repair technique. As the first step, abdominal fat is placed intradurally. B: A piece of fascia lata is placed intracranially to cover the osteodural defect. C: A graft of mucoperiosteum or a nasoseptal flap is placed extracranially as the final step of the dural repair. 
TABLE 1. Preoperative and postoperative clinical features in a series of 10 patients with craniopharyngiomas

\begin{tabular}{|c|c|c|c|c|c|c|c|c|c|c|}
\hline \multirow{2}{*}{$\begin{array}{c}\text { Case } \\
\text { No. }\end{array}$} & \multirow[b]{2}{*}{ Sex } & \multirow{2}{*}{$\begin{array}{l}\text { Age } \\
\text { (yrs) }\end{array}$} & \multicolumn{4}{|c|}{ Preop } & \multicolumn{4}{|c|}{ Postop } \\
\hline & & & Ophthal Disturb & Endocr Disturb & Neurol Disturb & $\mathrm{BMI}$ & Ophthal Disturb & Endocr Disturb & Neurol Disturb & BMI \\
\hline 1 & $F$ & 62 & BTH & HP & Headache & 21.4 & None & HP, DI & Headache & 23.9 \\
\hline 2 & $F$ & 72 & BTH & None & Headache & 22 & None & None & None & 23.2 \\
\hline 3 & $M$ & 52 & None & $\mathrm{HP}$ & Headache & 26.3 & $\mathrm{HQ}$ & HP, DI & None & 27.7 \\
\hline 4 & $\mathrm{~F}$ & 27 & BTH & None & Headache & 28.8 & BTH & HP, DI & None & 31 \\
\hline 5 & M & 45 & $\mathrm{HH}$ & None & None & 29.3 & $\mathrm{HQ}$ & HP, DI & None & 32.1 \\
\hline 6 & $\mathrm{~F}$ & 53 & $\mathrm{HH}$ & None & Headache & 29 & None & HP, DI & Headache & 23.7 \\
\hline 7 & $\mathrm{~F}$ & 36 & None & $\mathrm{HP}$ & Headache & 20.1 & None & HP, DI & None & 21.4 \\
\hline 8 & M & 69 & BTH & None & None & 26.5 & None & HP, DI & Headache & 25.9 \\
\hline 9 & M & 28 & $\mathrm{HH}$ & $\mathrm{HP}$ & Headache & 24.8 & None & HP, DI & Headache & 30.4 \\
\hline 10 & $\mathrm{~F}$ & 42 & $H Q$ & None & None & 24.8 & None & HP, DI & None & 27 \\
\hline
\end{tabular}

$\mathrm{BTH}=$ bitemporal hemianopia; disturb = disturbances; endocr = endocrinological; $\mathrm{HH}=$ homonymous hemianopia; $\mathrm{HP}=$ hypopituitarism; $\mathrm{HQ}=$ homonymous quadrantanopia; neurol = neurological; ophthal $=$ ophthalmological.

and 4 were men. The mean age was 48.6 years (SD 15.9 years). The tumor involved the anterior hypothalamus in all cases, and in 5 patients it was also extended to the posterior hypothalamus. The most common preoperative symptoms were headaches, which were reported by 7 of the 10 patients. Preoperative visual disturbances resulted in 4 cases of bitemporal hemianopia, 3 cases of lateral homonymous hemianopia, and 1 case of superior homonymous quadrantanopia (Table 1). As shown in Table 2, 6 cases were purely endoventricular and 4 were primarily suprasellar tumors with third ventricle involvement (or infundibulo-tuberal lesions) (Fig. 4). At presentation, partial hypopituitarism was observed in 3 cases and panhypopituitarism in 1 case. No case of preoperative DI was observed. The mean preoperative BMI was $23.5 \mathrm{~kg} / \mathrm{m}^{2}$ (SD $3.3 \mathrm{~kg} / \mathrm{m}^{2}$ ). No patient reported symptoms related to sleep-wake cycle or body temperature alterations.

Preoperatively, the BCT rhythms and sleep-wake cycle were pathological in most of the cases. Indeed, sleep efficiency was reduced (to $<85 \%$ ) presurgically in 8 patients (Table 2). Before surgery, 7 patients had 1-3 diurnal naps (mean duration 32 minutes); these occurred more fre- quently in the afternoon and evening (13:20-21:15). All naps started in light sleep. The circadian rhythm of the $\mathrm{BCT}$ was pathological in 5 cases.

Gross-total resection (GTR) was achieved in 8 cases. Intraoperatively, a subpial infiltration of the hypothalamus was observed in 5 cases (Fig. 5). Complications consisted of one transitory third cranial nerve palsy, which recovered after 6 months. At histological analysis, 5 patients presented with an adamantinomatous variant and 5 had a papillary form (Table 3).

At mean follow-up (median 8 months, range 6-15 months), one tumor progression was observed 2 years after a partial tumor resection (PTR), requiring a transcranial approach. Ophthalmological examination demonstrated the normalization of 5 cases with preoperative deficits, 1 case improved, and 1 patient remained stable (Table 2). Only 1 patient developed a homonymous quadrantanopia de novo after surgery. To some extent, hypopituitarism and DI developed in all patients but one after surgery. The mean BMI at follow-up was $26.6 \mathrm{~kg} / \mathrm{m}^{2}$ (SD $\left.3.6 \mathrm{~kg} / \mathrm{m}^{2}\right)$, with a mean increase of $2.9 \mathrm{~kg} / \mathrm{m}^{2}(\mathrm{SD} 2.7 \mathrm{~kg} /$ $\left.\mathrm{m}^{2}\right)$.

TABLE 2. Body core temperature and sleep-wake cycle findings at 24 hours in 10 patients with craniopharyngiomas

\begin{tabular}{|c|c|c|c|c|c|c|c|c|c|c|}
\hline \multirow[b]{2}{*}{$\begin{array}{l}\text { Case } \\
\text { No. }\end{array}$} & \multirow[b]{2}{*}{ Tumor Location } & \multirow[b]{2}{*}{$\begin{array}{c}\text { Hypothal } \\
\text { Involvement }\end{array}$} & \multicolumn{4}{|c|}{ Preop } & \multicolumn{4}{|c|}{ Postop } \\
\hline & & & $\begin{array}{c}\text { BCT } \\
\text { Rhythm }\end{array}$ & $\begin{array}{c}\text { Sleep-Wake } \\
\text { Efficiency }\end{array}$ & $\begin{array}{c}\text { No. of } \\
\text { Diurnal } \\
\text { Naps }\end{array}$ & $\begin{array}{c}\text { Dur of } \\
\text { Diurnal } \\
\text { Naps (mins) }\end{array}$ & $\begin{array}{c}\text { BCT } \\
\text { Rhythm }\end{array}$ & $\begin{array}{l}\text { Sleep-Wake } \\
\text { Efficiency }\end{array}$ & $\begin{array}{c}\text { No. of } \\
\text { Diurnal } \\
\text { Naps }\end{array}$ & $\begin{array}{c}\text { Dur of } \\
\text { Diurnal } \\
\text { Naps (mins) }\end{array}$ \\
\hline 1 & Endoventricular & Ant \& pst & Path & Path & 3 & 34 & Improved & Path & 4 & 50 \\
\hline 2 & Infundibulo-tuberal & Ant & Normal & Path & 1 & 45 & Normal & Path & 3 & 29 \\
\hline 3 & Endoventricular & Ant & Normal & Path & 2 & 46 & Path & Path & 3 & 42 \\
\hline 4 & Endoventricular & Ant & Path & Normal & 0 & & Path & Normal & 2 & 32 \\
\hline 5 & Infundibulo-tuberal & Ant & Path & Path & 2 & 6 & Normal & Normal & 6 & 50 \\
\hline 6 & Endoventricular & Ant \& pst & Path & Path & 1 & 25 & Normal & Normal & 4 & 35 \\
\hline 7 & Endoventricular & Ant \& pst & Path & Path & 3 & 38 & Improved & Normal & 2 & 48 \\
\hline 8 & Endoventricular & Ant \& pst & Path & Normal & 0 & & Improved & Normal & 0 & \\
\hline 9 & Infundibulo-tuberal & Ant \& pst & Normal & Path & 1 & 48 & Normal & Path & 2 & 100 \\
\hline 10 & Infundibulo-tuberal & Ant & Normal & Path & 0 & & Normal & Normal & 2 & 58 \\
\hline
\end{tabular}

Ant = anterior; dur = duration; hypothal = hypothalamus; path = pathological; pst = posterior . 


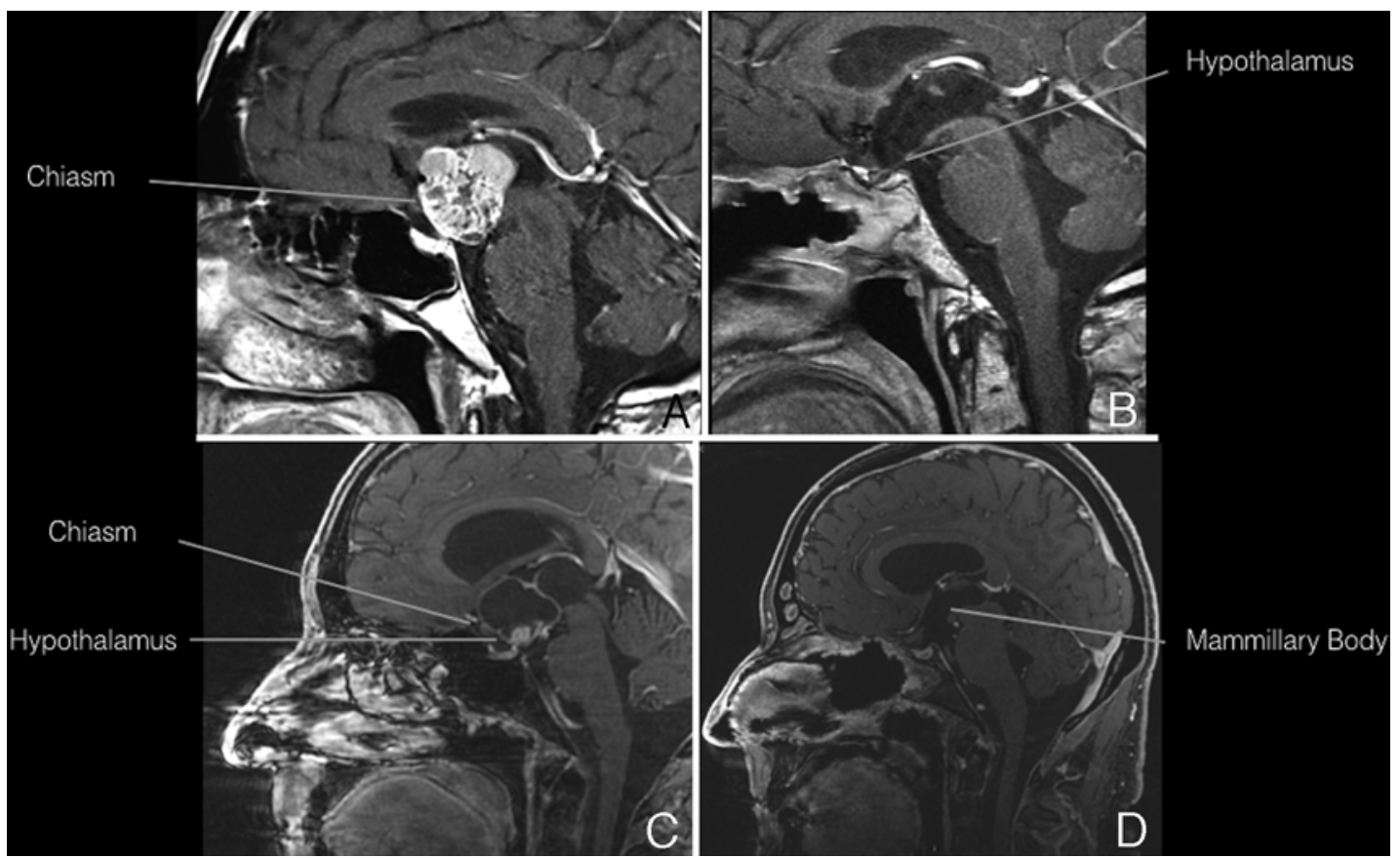

FIG. 4. Sagittal slices, T1-weighted MRI study obtained after the addition of gadolinium. The 2 variants of third ventricle craniopharyngioma are demonstrated. According to the system of Kassam et al. and Pascual et al., we classified as 1) infundibulo-tuberal (or not strictly intraventricular) those tumors arising from the pituitary stalk at its upper part, and thus extending primarily suprasellarly and involving the third ventricle floor during their growth; or 2) purely endoventricular those lesions completely within the third ventricle. A: An example of an infundibulo-tuberal craniopharyngioma is shown. In this kind of the tumor, the floor of the ventricle is disrupted or displaced circumferentially by the tumor during its extension. B: Postoperative MR image obtained in this case demonstrating complete tumor removal. C: A purely endoventricular tumor can be observed. In this case the third ventricle is displaced inferiorly by the tumor growth. D: Postoperative MR image obtained in this case demonstrating its radical removal.

At follow-up, the BCT rhythm normalized in 2 cases, improved in 3 cases, and remained pathological in 1 case; 1 patient presented with alterations de novo. Sleep efficiency became normal in 4 of 8 cases after surgery. After surgery, 9 patients had 2-6 diurnal naps with a mean duration of 50 minutes, with distribution during the entire range of waking hours (07:09-22:04).

\section{Discussion}

In our study, we have observed that among the broad spectrum of hypothalamic disturbances related to third ventricle craniopharyngiomas, BCT rhythm and sleepwake cycle disturbances are not uncommon. Indeed, we have observed that these functions were deregulated preoperatively in the majority of cases in our series, despite patients being unaware and not reporting such disturbances, probably because visual, endocrinological, or other neurological deficits overshadowed the symptoms. Moreover, considering their complexity, which makes extensive investigation difficult, and their subtle clinical manifestations, these disorders are often ignored, disregarded, or misinterpreted. This can explain the paucity of attention paid to these alterations in the current literature on craniopharyngiomas affecting the third ventricle. . $^{1,5,6,9,14,16,22,28}$ In our series, postoperative outcome after the EEA is encouraging, with complete recovery of sleep efficiency in $50 \%$ of cases and normalization or improvement of BCT rhythm in 5 of 6 cases with preoperative disturbances.
Furthermore, only 1 patient presented with a de novo onset of temperature rhythm alteration at follow-up.

Despite our restricted series not allowing definitive conclusions to be drawn, we observed that preoperatively most of the patients with BCT rhythm alterations were affected by endoventricular tumors rather than infundibulo-tuberal forms. Indeed, according to Kassam et al., craniopharyngiomas can be classified depending on their relationship with the pituitary stalk. ${ }^{15}$ Pascual et al. have recently proposed the use of this same scheme for tumors of the third ventricle, dividing infundibulo-tuberal tumors from purely endoventricular ones. The first are craniopharyngiomas arising in the upper part of the stalk-infundibulum complex. . $^{24-27,29}$ These authors argued that the growth of the tumor could lead to a displacement or disruption of the third ventricle floor, which results in tight adherence all around the tumor. This close relationship represents the main surgical risk for intraoperative hypothalamic damage in these tumors. Conversely, in purely endoventricular forms, the floor of the third ventricle is pushed inferiorly by the tumor.

Furthermore, we observed that papillary histotypes are more commonly associated with preoperative BCT rhythm alterations than adamantinomatous ones. Indeed, of 6 cases with such disturbances, 4 were papillary tumors. As observed elsewhere, these features could be explained by the propensity of papillary histotypes to show an expansive growth, in comparison with the infiltrative behavior typical of the adamantinomatous form. ${ }^{14}$ Conversely, the 


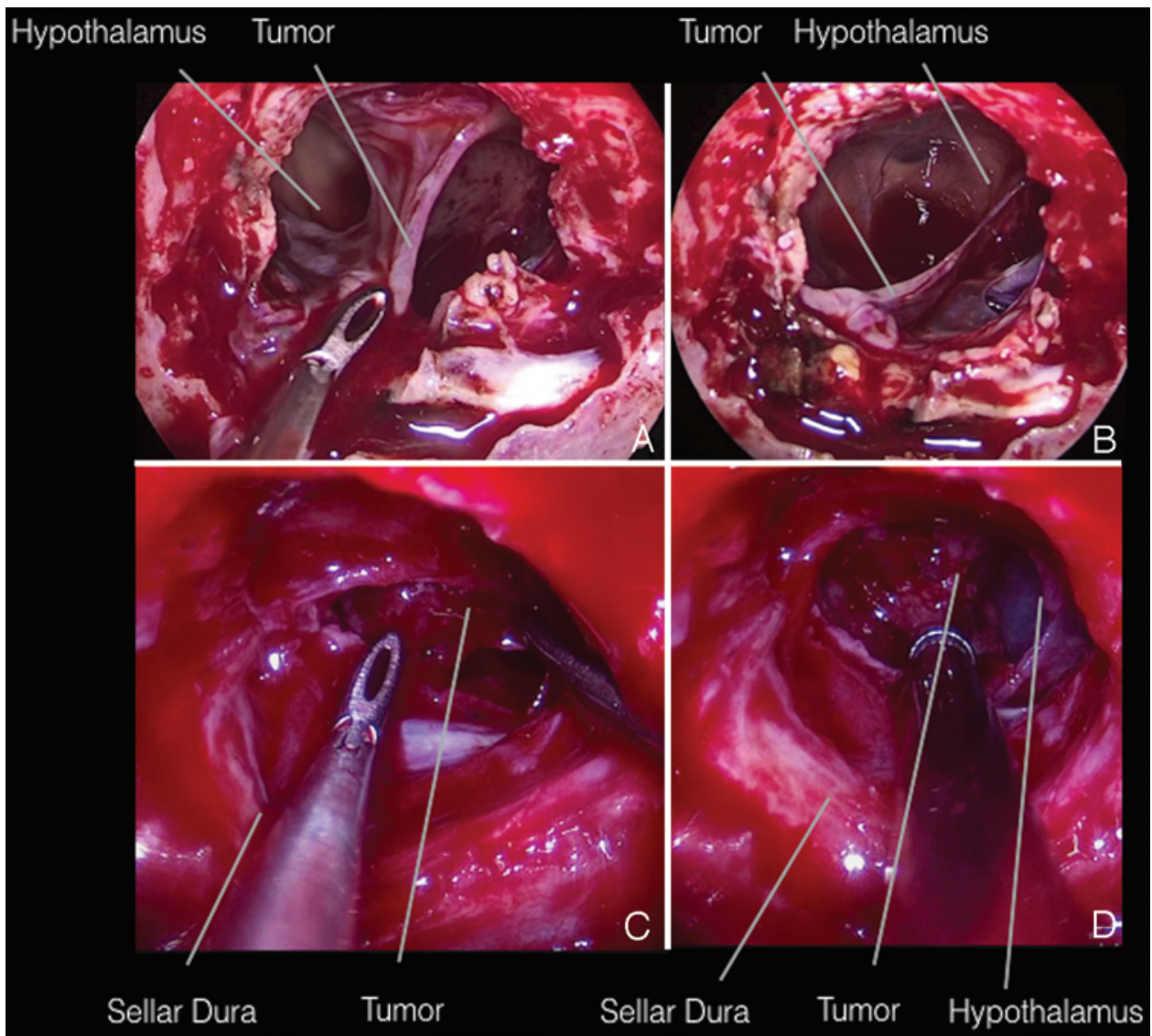

FIG. 5. Intraoperative endoscopic endonasal images obtained using a $0^{\circ}$ scope. The different adhesion to the hypothalamus and other structures is shown. A and B: The tumor is progressively removed from the third ventricle, respecting the hypothalamic structures. C and D: The mass cannot be resected from the hypothalamus, to which it is firmly adherent. To avoid any permanent damage, the tumor removal is abandoned.

location in the anterior and/or posterior hypothalamus has not been associated with more preoperative BCT rhythm dysfunction in our series.

Assessing the outcome of this disturbance after surgery, we noticed that it recovered or improved in most of the cases, with only 1 case of de novo onset. This positive outcome has been observed more frequently in endoventricular forms, but it is unknown whether this is due to the different preoperative frequency of this disturbance. The EEA allows us to remove the tumor while respecting as much as possible the integrity and vascular supply of the hypothalamus, and this might favor the recovery from this alteration in BCT rhythm. .,9,11,16,20,23,30,31

In our series, we observed that sleep-wake cycle disturbances were very common preoperatively. However, this may be due to a possible bias of the study, because these

TABLE 3. Histological and molecular features in a series of 10 patients with craniopharyngiomas

\begin{tabular}{cllcll}
\hline Case No. & EOR & Histological Finding & Intraop Subpial Infiltration & BRAF & $\beta$-Catenin \\
\hline 1 & GTR & Papillary & Intrapial & V600E & WT \\
\hline 2 & GTR & Adamantinomatous & Extrapial & WT & G34R \\
\hline 3 & GTR & Adamantinomatous & Intrapial & WT & G34E \\
\hline 4 & GTR & Adamantinomatous & Extrapial & WT & WT \\
\hline 5 & PTR & Adamantinomatous & Extrapial & WT & D32Y \\
\hline 6 & GTR & Papillary & Extrapial & V600E & WT \\
\hline 7 & GTR & Papillary & Intrapial & V600E & WT \\
\hline 8 & PTR & Papillary & Intrapial & V600E & WT \\
\hline 10 & GTR & Adamantinomatous & Intrapial & WT & S33C \\
\hline GTR & Papillary & Extrapial & V600A & WT \\
\hline
\end{tabular}

EOR = extent of resection; $W T$ = wild type. 
recordings have been performed in the days and nights immediately before the surgery, and thus the nocturnal sleep efficiency could be reduced by other confounding factors. We have observed that extrapial tumors had a better outcome for nocturnal sleep efficiency. This could possibly be explained by the biologically infiltrative nature of the intrapial forms, which overwhelm the pial layer with an inward spread in the hypothalamic parenchyma. Conversely, a postoperative increase in the number and time of diurnal naps, despite an improvement of sleep efficiency, was generally observed in our series, and this peculiar alteration needs to be confirmed with longer follow-up.

We observed, as in other large series, a good ophthalmological outcome, with normalization or improvement in the vast majority of cases with visual disturbances. ${ }^{2-4,8,21}$ Also the GTR rate achieved was satisfactory, with minimal complications, consisting of only 1 case of transient third cranial nerve palsy. On the other hand, the endocrinological outcome is poor for these tumors, in accordance with previous data; a vast majority of patients have postoperative permanent complete pituitary insufficiency. Indeed, our surgical goal consisted of the most extensive tumor resection possible, preserving the hypothalamic functions, which were normal or only subclinically impaired preoperatively. It is reported in the literature that in cases of severe preoperative hypothalamic disturbances, major surgery with a resective aim could be harmful.

Assessing the BMI alterations, we observed a mean increase of $2.9 \mathrm{~kg} / \mathrm{m}^{2}$. Preoperatively, 3 patients presented with a BMI greater than 30 . We observed, as suggested by Elowe-Gruau et al., ${ }^{10}$ that patients who undergo a PTR might present with a lesser BMI increase.

Due to the rarity of these tumors, this study is limited by the restricted number of cases and the short follow-up, and therefore our results should be considered as preliminary. However, this method of analysis has been revealed to be satisfactory, allowing us to identify these alterations preoperatively and to assess their outcome. Despite the fact that the sleep-wake cycle recordings were obtained during the days of hospitalization just before the surgery and that this might have affected the reliability of these results, the cases more affected by BCT or sleep-wake dysfunction seem to be those with biologically unfavorable features, such as hypothalamic disruption by the tumor, intrapial infiltration, and papillary histotypes. Larger studies are needed to confirm these preliminary data.

\section{Conclusions}

The alterations of the BCT rhythm and sleep-wake cycle in patients with third ventricle craniopharyngiomas are largely unknown, and the impact of endoscopic endonasal surgery on these alterations has been scarcely considered in the literature. Our methods of investigation of these disturbances have provided satisfactory results, allowing the identification of alterations not reported by the patients. The EEA in this series has been revealed to be safe and effective, with a good rate of GTR and an excellent visual outcome. In our experience, this approach allows us to spare as much as possible the hypothalamic structures and their vascular supply, contributing to avoiding BCT rhythm and sleep-wake cycle sequelae.
Our results seem to indicate that the cases with biologically unfavorable elements such as hypothalamic disruption by the tumor, intrapial infiltration, and papillary histotypes present more frequently with BCT rhythm alterations and sleep-wake cycle disturbances. Despite the limitation of the sample size and the short follow-up period in our series, we consider these results encouraging and believe that additional series are needed to confirm these preliminary findings.

\section{Acknowledgments}

This work was supported in part by Italian GovernmentMinistero della Salute Grant No. RF-2011-02350857 to Dr. Tallini and Grant No. GR-2011-02350937 to Dr. de Biase.

\section{References}

1. Bahuleyan B, Menon G, Nair S: Immediate postoperative death due to hypothalamic injury following surgery for craniopharyngioma. J Clin Neurosci 16:850-851, 2009

2. Baldauf J, Hosemann W, Schroeder HW: Endoscopic endonasal approach for craniopharyngiomas. Neurosurg Clin $\mathbf{N}$ Am 26:363-375, 2015

3. Cavallo LM, Frank G, Cappabianca P, Solari D, Mazzatenta D, Villa A, et al: The endoscopic endonasal approach for the management of craniopharyngiomas: a series of 103 patients. J Neurosurg 121:100-113, 2014

4. Cavallo LM, Solari D, Esposito F, Cappabianca P: The endoscopic endonasal approach for the management of craniopharyngiomas involving the third ventricle. Neurosurg Rev 36:27-38, 2013

5. Cohen RA, Albers HE: Disruption of human circadian and cognitive regulation following a discrete hypothalamic lesion: a case study. Neurology 41:726-729, 1991

6. Crowley RK, Woods C, Fleming M, Rogers B, Behan LA, O'Sullivan EP, et al: Somnolence in adult craniopharyngioma patients is a common, heterogeneous condition that is potentially treatable. Clin Endocrinol (Oxf) 74:750-755, 2011

7. Daubenbüchel AM, Müller HL: Neuroendocrine disorders in pediatric craniopharyngioma patients. J Clin Med 4:389413, 2015

8. de Lara D, Ditzel Filho LF, Muto J, Otto BA, Carrau RL, Prevedello DM: Surgical management of craniopharyngioma with third ventricle involvement. Neurosurg Focus 34 (1 Suppl): Video 5, 2013

9. de Vetten L, Bocca G: Systemic effects of hypothermia due to hypothalamic dysfunction after resection of a craniopharyngioma: case report and review of literature. Neuropediatrics 44:159-162, 2013

10. Elowe-Gruau E, Beltrand J, Brauner R, Pinto G, SamaraBoustani D, Thalassinos C, et al: Childhood craniopharyngioma: hypothalamus-sparing surgery decreases the risk of obesity. J Clin Endocrinol Metab 98:2376-2382, 2013

11. Fjalldal S, Holmer H, Rylander L, Elfving M, Ekman B, Osterberg K, et al: Hypothalamic involvement predicts cognitive performance and psychosocial health in long-term survivors of childhood craniopharyngioma. J Clin Endocrinol Metab 98:3253-3262, 2013

12. Frank G, Pasquini E, Doglietto F, Mazzatenta D, Sciarretta V, Farneti G, et al: The endoscopic extended transsphenoidal approach for craniopharyngiomas. Neurosurgery 59 (1 Suppl 1):ONS75-ONS83, 2006

13. Iber C, Ancoli-Israel S, Chesson AL Jr, Quan SF (eds): The AASM Manual for the Scoring of Sleep and Associated Events: Rules, Terminology and Technical Specifications. Westchester, IL: American Academy of Sleep Medicine, 2007 
14. Joustra SD, Thijs RD, van den Berg R, van Dijk M, Pereira $\mathrm{AM}$, Lammers GJ, et al: Alterations in diurnal rhythmicity in patients treated for nonfunctioning pituitary macroadenoma: a controlled study and literature review. Eur J Endocrinol 171:217-228, 2014

15. Kassam AB, Gardner PA, Snyderman CH, Carrau RL, Mintz AH, Prevedello DM: Expanded endonasal approach, a fully endoscopic transnasal approach for the resection of midline suprasellar craniopharyngiomas: a new classification based on the infundibulum. J Neurosurg 108:715-728, 2008

16. Manley PE, McKendrick K, McGillicudy M, Chi SN, Kieran MW, Cohen LE, et al: Sleep dysfunction in long term survivors of craniopharyngioma. J Neurooncol 108:543-549, 2012

17. Marucci G, de Biase D, Visani M, Giulioni M, Martinoni M, Volpi L, et al: Mutant BRAF in low-grade epilepsy-associated tumors and focal cortical dysplasia. Ann Clin Transl Neurol 1:130-134, 2014

18. Marucci G, de Biase D, Zoli M, Faustini-Fustini M, Bacci A, Pasquini E, et al: Targeted BRAF and CTNNB1 next-generation sequencing allows proper classification of nonadenomatous lesions of the sellar region in samples with limiting amounts of lesional cells. Pituitary 18:905-911, 2015

19. Mojón A, Fernández JR, Hermida RC: CronoLab: an interactive software package for chronobiologic time series analysis written for the Macintosh computer. Chronobiol Int 9:403412, 1992

20. Müller HL: Craniopharyngioma and hypothalamic injury: latest insights into consequent eating disorders and obesity. Curr Opin Endocrinol Diabetes Obes 23:81-89, 2016

21. Nishioka H, Fukuhara N, Yamaguchi-Okada M, Yamada S: Endoscopic endonasal surgery for purely intrathird ventricle craniopharyngioma. World Neurosurg 91:266-271, 2016

22. O'Gorman CS, Simoneau-Roy J, Pencharz P, MacFarlane J, MacLusky I, Narang I, et al: Sleep-disordered breathing is increased in obese adolescents with craniopharyngioma compared with obese controls. J Clin Endocrinol Metab 95:2211-2218, 2010

23. Özyurt J, Müller HL, Thiel CM: A systematic review of cognitive performance in patients with childhood craniopharyngioma. J Neurooncol 125:9-21, 2015

24. Pascual JM, Prieto R, Carrasco R, Barrios L: Displacement of mammillary bodies by craniopharyngiomas involving the third ventricle: surgical-MRI correlation and use in topographical diagnosis. J Neurosurg 119:381-405, 2013

25. Pascual JM, Prieto R, Carrasco R, Castro-Dufourny I, Barrios L: Craniopharyngioma adherence to the hypothalamus. Neurosurg Focus 37(2):1-7, 2014 (Letter)
26. Pascual JM, Prieto R, Castro Dufourny I, Gil Simoes R, Carrasco R: Craniopharyngiomas of the third ventricle: topographical concepts of surgical interest. Br J Neurosurg 27:268-269, 2013

27. Pascual JM, Prieto R, Dufourny IC, Simoes RG, Carrasco $\mathrm{R}$ : Hypothalamus-referenced classification for craniopharyngiomas: evidence provided by the endoscopic endonasal approach. Neurosurg Rev 36:337-339, 2013

28. Pickering L, Jennum P, Gammeltoft S, Poulsgaard L, FeldtRasmussen U, Klose M: Sleep-wake and melatonin pattern in craniopharyngioma patients. Eur J Endocrinol 170:873884, 2014

29. Prieto R, Pascual JM: Accurate craniopharyngioma topography for patient outcome improvement. World Neurosurg 82:e555-e559, 2014

30. Steňo J, Bízik I, Steňo A, Matejčík V: Craniopharyngiomas and the hypothalamus. J Neurosurg 119:1646-1650, 2013

31. Sterkenburg AS, Hoffmann A, Gebhardt U, Warmuth-Metz M, Daubenbüichel AM, Müller HL: Survival, hypothalamic obesity, and neuropsychological/psychosocial status after childhood-onset craniopharyngioma: newly reported longterm outcomes. Neuro Oncol 17:1029-1038, 2015

\section{Disclosures}

The authors report no conflict of interest concerning the materials or methods used in this study or the findings specified in this paper.

\section{Author Contributions}

Conception and design: Zoli, Sambati. Acquisition of data: Zoli, Sambati, Milanese, Foschi, Marucci, de Biase, Cecere, Mignani. Analysis and interpretation of data: Zoli, Sambati, Milanese, Foschi, Faustini-Fustini, Marucci, de Biase, Cecere, Mignani. Drafting the article: Zoli, Sambati, Milanese, Foschi, FaustiniFustini, Marucci, de Biase, Provini. Critically revising the article: Faustini-Fustini, Tallini, Sturiale, Frank, Cortelli, Provini. Reviewed submitted version of manuscript: Faustini-Fustini, Tallini, Sturiale, Frank, Pasquini, Cortelli, Mazzatenta, Provini. Statistical analysis: Pasquini, Mazzatenta, Provini. Study supervision: Sturiale, Frank, Pasquini, Cortelli, Mazzatenta, Provini.

\section{Correspondence}

Matteo Zoli, Center of Surgery for Pituitary Tumors and Endoscopic Skull Base Surgery, IRCCS Istituto delle Scienze Neurologiche, Bologna 40139, Italy. email: matteo.zoli4@unibo.it. 